\title{
Identifying Drought Tolerant Genotypes of Rice (Oryza sativa L.) Using Participatory Research Approach for Resource Poor Farmers of Orissa
}

\author{
A.K. Mall", P. Swain and O.N. Singh \\ Central Rice Research Institute (CRRI), Cuttack-753 006, Orissa, India \\ *Corresponding author
}

\section{A B S T R A C T}

To encourage rice-rice cropping system, enhance yield and livelihood in rainfed areas, Drought Breeding Network, Cuttack conducted "Participatory Varietal

Keywords

Rice, Yield,

DSI, DTE and

PVS.

Article Info

Accepted:

04 June 2017

Available Online:

10 July 2017 Selection (PVS)" trial at Samian and Berna village under drought prone rainfed condition during wet season. The management practices were consistent with local crop husbandry used by farmers and evaluations were made by the farmers. The genotypes viz., CR 2624 and IR 74371-70-1-1 were stable, however IR 74371-3-11 was found to be suited for fragile environments. The genotypes IR 74371-70-11, IR 74371-3-1-1, CR 2624 and IR 55419-04 yielded maximum than best check (Khandagiri) and exhibited low DSI and high DTE for grain yield also. These genotypes registered above $4.5 \mathrm{t} \mathrm{ha}^{-1}$ yield at on-station trial, early vegetative vigour, good drought score. Both male and female farmers scored each genotype for individual traits considered important by them and CR 2624, IR 74371-70-1-1 and IR 74371-3-1-1 genotypes were top three during participatory varietal selection.

\section{Introduction}

The demand for rice in India is projected to be $128 \mathrm{mt}$ by 2012 and will require a production level of $3,000 \mathrm{~kg} \mathrm{ha}^{-1}$ significantly greater than the present average yield of $1,930 \mathrm{~kg} \mathrm{ha}^{-1}$ (Pandey et al., 2007). Indian agriculture is mainly dependent on the climate of India: a favorable southwest summer monsoon is critical in securing water for irrigating Indian crops. In some parts of India, the failure of the monsoon results in water shortage, resulting in below-average crop yield. This is particularly true of major drought-prone regions such as southern and eastern Maharashtra, northern Karnataka, Andhra Pradesh, Orissa, Gujarat, and Rajasthan.
Groundwater has been depleted at alarming rates. Out of a total 610 districts nationally, 278 districts in 11 states have been declared as drought-hit during wet season, 2009.Drought in India was also reduced production of the 2010 Kharif crops including rice, coarse grains and pulses in nearly half the districts of the country.

\section{Target Environments (TPE)}

Participatory Varietal Selection (PVS)" trials were conducted at Samian and Berna villages of Cuttack District, Orissa to identify adaptable variety for rainfed drought prone 
condition with drought tolerance and high yield potential. Most farmers of these villages are resource-poor, with limited resources for irrigation facility. Low productivity is the main cause of high poverty. The coverage of land by rice crop during wet season was 99 per cent, while the coverage of rice during dry season was only 54 per cent. The early season drought occurs in most areas, affecting the time of transplanting and the growth of direct seeded rice. The irrigation sources of villages is Kalakala Minor Irrigation Project which is popularly known as Gapala Bandha and supplies water during both wet and dry seasons. The average yield of modern varieties in up, medium and low land was 2.86, 3.67 and $3.72 \mathrm{t} \mathrm{ha}^{-1}$ at both the villages. In drought cases, no yield was obtained in majority of the fields. Therefore, to enhance yield and livelihood of target area, PVS trials under Drought Breeding Network, Cuttack were conducted at Samia and Berna to identify adaptable variety for rainfed drought prone condition with drought tolerance and high yield potential.

\section{Materials and Methods}

\section{Plant materials}

Central Rice Research Institute (CRRI), Cuttack in collaboration with International Rice Research Institute (IRRI), Philippines are striving hard with pragmatic approach to develop drought tolerant rice varieties which can mitigate the changing climatic scenario and provide good stable yield in years of drought. Four hundred fifty genotypes were tested for yield and yield attributes under irrigated and drought conditions at CRRI, Cuttack under IRRI-India drought breeding network (DBN). Out of these, 15 promising genotypes were evaluated and tested along with four checks at four farmer's field in Samia and Berna villages of district Jajpur under participatory varietal selection trials.
These genotypes responded well under severe drought conditions and displayed good drought score, recovery and early vegetative vigour, simultaneously, substantial yield also.

\section{Experimental design}

Tested genotypes were grown under rainfed conditions representing a sample of environments during wet season, 2009 at four farmer's field. The rain fall during the cropping season was less and erratic in these parts of Orissa and faced early and late season drought stress. Rice varieties at farmer's field 1: upland area $\left(\mathrm{E}_{1}\right)$ were directly sown at 2-3 $\mathrm{cm}$ soil depth in dry and pulverized soil by hand plough with the seed rate of $60 \mathrm{Kg} \mathrm{ha}^{-1}$ to maintain 3-4 seeds per hill. This method gave uniform seedling emergence for all the plots in 6-8 days. Each plot was $4 \mathrm{~m}$ long and $5.0 \mathrm{~m}$ wide, row to row distance was $15 \mathrm{~cm}$ and plant to plant distance was $10 \mathrm{~cm}$ each plot. Fertilizer was applied at the rate of 80 , 40 , and $40 \mathrm{~kg} \mathrm{ha}^{-1}$ of $\mathrm{N}, \mathrm{P}_{2} \mathrm{O}_{5}$, and $\mathrm{K}_{2} \mathrm{O}$, respectively. One third of nitrogen and entire dose of $\mathrm{P}_{2} \mathrm{O}_{5}$ and $\mathrm{K}_{2} \mathrm{O}$ were given as basal dressing and remaining $\mathrm{N}$ was split into two doses applied at maximum tillering and flowering stages. Weeds were controlled by treating plot by pre-emergence herbicide (Petrilachlore) after three days of sowing followed by two hand weeding. At farmer's field 2: lowland $\left(E_{2}\right)$ and farmer's field 3 and 4: medium land $\left(E_{3}\right.$ and $\left.E_{4}\right)$, seeds were sown in the nursery and 21-day-old seedlings were transplanted to the main field. One seedling was transplanted per hill at a spacing of $15 \mathrm{~cm}$ between hills in plots $18 \mathrm{~m}^{2}$.

Inorganic NPK fertilizer was applied at the rate of 100: 60: $40 \mathrm{~kg} \mathrm{ha}^{-1}$. Weeds were controlled by application of pre emergence herbicide Pretilachlor 4 days after transplanting (DAT) and hand weeding. The other trial management practices were consistent with local crop husbandry used by 
the farmers and evaluations were made by the farmers (male and female).

\section{Observations and evaluation}

Observations on days to 50 per cent flowering (DFF) and grain yield (GY) were recorded on the plot basis. The effect of drought was assessed as percentage reduction in mean performance of characteristics under rain-fed condition relatively to the performance of the same trait under irrigated condition.

Drought susceptibility index (DSI) for grain yield and other characters was calculated using the following formula (Fischer and Maurer, 1978). Drought tolerance efficiency (DTE) was estimated by the equation of Fischer and Wood (1981).

\section{Results and Discussion}

\section{Drought Susceptible Index (DSI)}

The DSI and DTE for the grain yield are presented in table 1. Large values indicate greater drought susceptibility (Winter et al., 1988). Differences in DSI between genotypes were estimated for days to 50 per cent flowering and grain yield in this study (Fig. 1). The mean values of DSI for grain yield were below one, indicating the relative tolerance of this trait to drought while genotypes showed delay in flowering and more prone to drought stress.

Based upon the value and direction of desirability, ranking was done for different genotypes as highly drought tolerant (DSI<0.50), drought tolerant (DSI: 0.510.75 ), moderately drought tolerant (DSI: 0.76$1.00)$ and drought susceptible (DSI $>1.00$ ). Seven genotypes (63\% of total) at all farmer's field were identified as drought tolerant genotypes $(\mathrm{DSI}<1)$ while, rest of the genotypes were identified as susceptible genotypes (DSI >1) for grain yield. An overall appraisal revealed that IR 74371-3-1-1 and IR 78877-181-B-1-2 emerged as highly tolerant genotypes while six genotypes viz., IR 79906B-5-3-3, IR 72267-16-B-B-1, IR 55419-04 and CR 2624 grouped into moderately tolerant group. Furthermore, IR 74371-70-1-1 (0.74) recorded as drought tolerant on pool basis. Comparison across the farmer's field indicated that the genotypes IR 74371-3-1-1 emerged as highly tolerant genotypes for grain yield.

Earlier Prakash (2007) and Bandyopadhyay (2008) reported similar findings. The reduction in grain yield was observed under farmer's field for the different genotypes while experimental mean reduce up to 30.43 per cent. The similar findings were found by (Wonprasaid et al., 1996). Differences among genotypes in yield under stress were partitioned into differences in yield potential, drought escape, and drought tolerance. Phenotypic traits related to yield under stress were divided into those reflecting drought escape and those reflecting drought tolerance.

However, the field data also indicated that considerable progress in yield under stress should be possible by selection for earlier flowering and improved yield potential alone (Fussell et al., 1991).

In present study, depletion of soil moisture, which was associated with forced maturity during dough stage, might have resulted in decreased grain yield.

The present study revealed that among the seven genotypes are drought tolerant genotypes, as indicated by their relatively low DSI values for grain yield at farmer's field. Genotypes with lowest DSI, particularly for grain yield would serve as useful donors for drought breeding programme. The use of DSI is likely to be most beneficial in selecting 
parents for development of drought tolerant populations, especially when yield potential vary greatly among the tested genotypes.

\section{Drought Tolerance Efficiency (DTE)}

Drought tolerance efficiency (DTE) value which was one of the drought resistance parameters were ranged from 55-90 per cent in $F_{1}, 58-96$ in $F_{2}, 55-89$ in $F_{3}$ and 59-93 in $\mathrm{F}_{4}$. Thus, IR 74371-3-1-1, IR 78877-181-B-12, IR 78875-53-2-2-2, CR 2624, IR 55419-04, IR 72267-16-B-B-1 and IR 79906-B-5-3-3 showed high DTE at all four farmer's field. On the other hand, IR 74371-3-1-1 and IR 78877-181-B-1-2 had lowest DSI. Results of this study have showed a parallelism with Parameshwarappa et al., (2008) findings.
They reported that minimum yield reduction was realized in the genotypes which had the highest DTE and the lowest DSI. While, IR 74371-3-1-1, CR 2624 and IR 74371-70-1-1 were most drought resistant genotypes with the minimum yield reduction and also highest DTE and lowest DSI; IR 78875-131-B-14-1 and IR 74371-46-1-1 and all the checks were the most drought susceptible genotypes with maximum yield losses and lowest DTE, also the highest DSI. Desmukh et al., (2004) reported that the drought resistant genotypes had highest DTE, minimum DSI and minimum reduction in grain yield due to moisture stress. Considering the assimilate partitioning in component traits of rice, tolerant genotypes increased the grain yield.

Fig.1 Drought Susceptibility Index (DSI) for days to 50 per cent flowering and grain yield

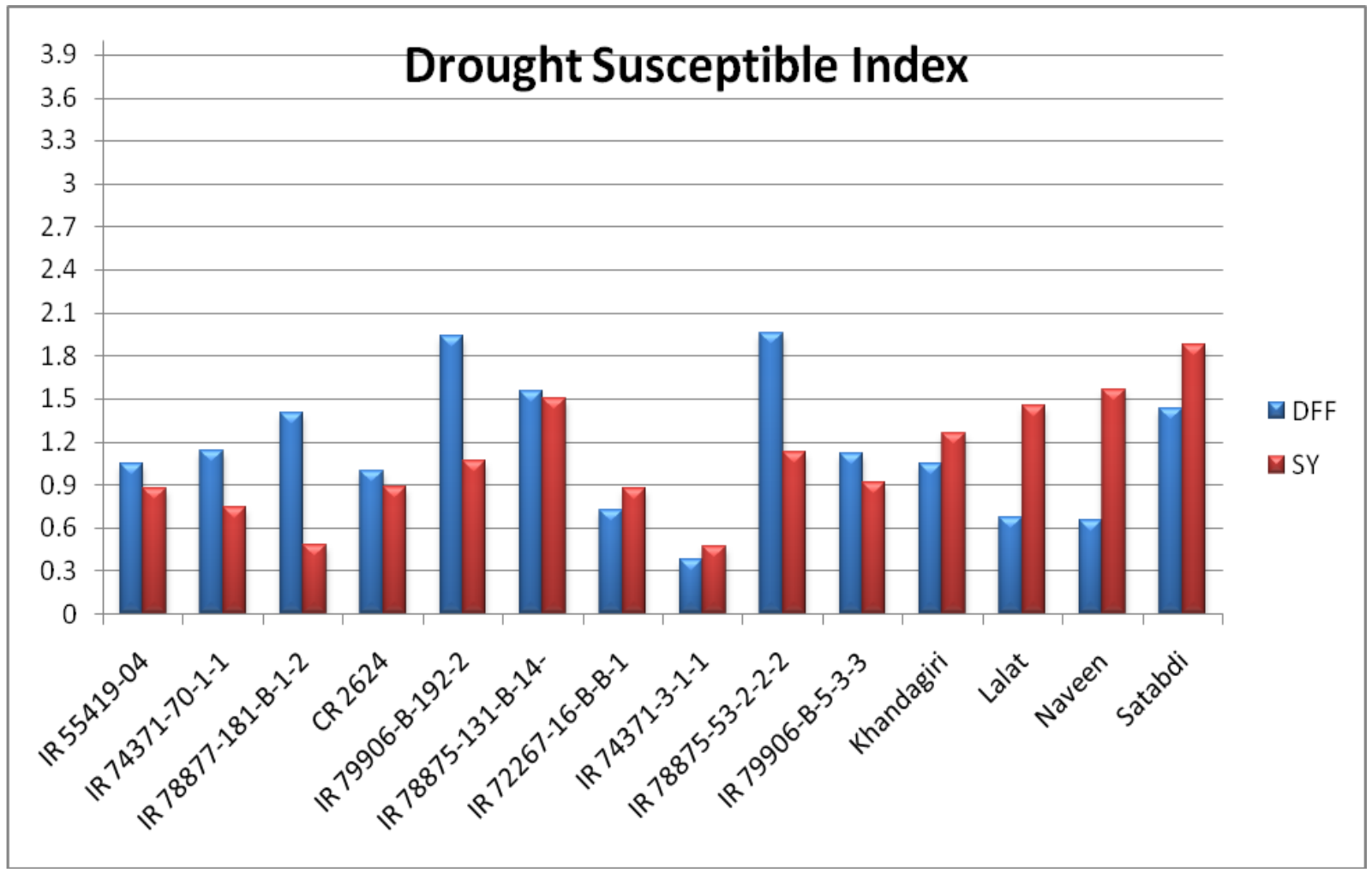


Table.1 Mean yield and drought susceptible index and tolerance efficiency of 15 genotypes grown at four farmer's field

\begin{tabular}{|c|c|c|c|c|c|c|c|c|c|c|c|c|}
\hline \multirow{2}{*}{$\begin{array}{l}\text { S. } \\
\text { No. }\end{array}$} & \multirow[t]{2}{*}{ Genotypes } & \multirow{2}{*}{$\begin{array}{l}\text { Mean yield } \\
\left(\mathrm{Kg} \mathrm{ha}^{-1}\right)\end{array}$} & \multicolumn{5}{|c|}{ Drought Susceptibility Index (DSI) } & \multicolumn{5}{|c|}{ Drought Tolerance Efficiency (DTE) } \\
\hline & & & Pooled & $\mathbf{E}_{1}$ & $\mathbf{E}_{2}$ & $\mathbf{E}_{3}$ & $\mathbf{E}_{4}$ & Pooled & $\mathbf{E}_{1}$ & $\mathbf{E}_{2}$ & $\mathbf{E}_{3}$ & $\mathbf{E}_{4}$ \\
\hline 1 & IR 72267-16-B-B-1 & 3243.33 & 0.87 & 0.85 & 0.82 & 0.66 & 0.82 & 80 & 77 & 80 & 83 & 80 \\
\hline 2 & IR 74371-46-1-1 & 3187.50 & 1.18 & 0.93 & 1.22 & 0.96 & 1.21 & 73 & 75 & 71 & 75 & 71 \\
\hline 3 & IR 74371-3-1-1 & 3521.67 & 0.47 & 0.37 & 0.60 & 0.41 & 0.36 & 89 & 90 & 86 & 89 & 91 \\
\hline 4 & IR 79906-B-192-2 & 3237.50 & 1.07 & 1.06 & 0.56 & 1.07 & 1.18 & 75 & 71 & 86 & 72 & 72 \\
\hline 5 & IR 78875-53-2-2-2 & 3338.33 & 1.13 & 1.07 & 1.03 & 0.99 & 0.99 & 83 & 79 & 81 & 83 & 88 \\
\hline 6 & IR 55419-04 & 3437.50 & 0.88 & 0.76 & 0.84 & 0.78 & 0.83 & 80 & 79 & 80 & 80 & 80 \\
\hline 7 & IR 74371-70-1-1 & 3523.33 & 0.74 & 0.79 & 0.78 & 0.64 & 0.51 & 74 & 71 & 75 & 74 & 76 \\
\hline 8 & IR 78875-131-B-14-1 & 2878.33 & 1.50 & 1.34 & 1.21 & 1.31 & 1.60 & 66 & 64 & 71 & 66 & 62 \\
\hline 9 & IR 78877-181-B-1-2 & 3349.17 & 0.48 & 0.66 & 0.17 & 0.63 & 0.28 & 89 & 82 & 96 & 84 & 93 \\
\hline 10 & IR 79906-B-5-3-3 & 3105.83 & 0.92 & 0.76 & 0.91 & 0.83 & 0.87 & 79 & 79 & 78 & 78 & 79 \\
\hline 11 & CR 2624 & 3503.33 & 0.89 & 0.82 & 0.80 & 0.79 & 0.84 & 80 & 78 & 81 & 80 & 80 \\
\hline 12 & Khandagiri & 3200.50 & 1.26 & 1.19 & 1.09 & 1.19 & 1.11 & 71 & 68 & 74 & 69 & 73 \\
\hline 13 & Lalat & 2953.83 & 1.45 & 1.25 & 1.47 & 1.32 & 1.26 & 67 & 66 & 65 & 66 & 70 \\
\hline 14 & Satabdi & 2441.67 & 1.88 & 1.66 & 1.76 & 1.75 & 1.70 & 57 & 55 & 58 & 55 & 59 \\
\hline 15 & Naveen & 2606.67 & 1.56 & 1.48 & 1.42 & 1.32 & 1.47 & 64 & 60 & 66 & 66 & 65 \\
\hline \multicolumn{2}{|c|}{ Mean } & 43.67 .33 & 1.09 & 1.00 & 0.98 & 0.98 & 1.01 & 75 & 73 & 77 & 75 & 76 \\
\hline
\end{tabular}

Table.2 Ranking of varieties in Participatory Varietal Selection (PVS) trial at Samian and Berna

\begin{tabular}{|l|c|c|c|}
\hline \multirow{2}{*}{ Varieties } & First & Second & Third \\
\cline { 2 - 4 } & \multicolumn{3}{|c|}{ Figures in per cent } \\
\hline CR 2624 & 30 & 12 & 33 \\
\hline IR 74371-70-1-1 & 23 & 38 & 5 \\
\hline IR 74371-3-1-1 & 17 & 20 & 17 \\
\hline Khandagiri & 7 & 2 & 12 \\
\hline IR 55419-04 & 7 & 2 & 8 \\
\hline
\end{tabular}




\section{Participatory varietal selection}

Participatory varietal selection is a farmer participatory approach for identifying farmerpreferred varieties. However, in the formal testing system varieties are identified for their superiority over the existing released varieties and much attention is given to grain yield and adaptability in the target area for promotion or release (Virk and Witcombe, 2008). Farmerrelevant traits other than yield are rarely considered while, promoting an entry although farmers are known to tradeoff multiple traits while selecting a variety. Participatory approaches that relied on focus group discussions (FGD) provided farmers' perceptions that were not obtained in the onstation trials and researcher managed FFTs, particularly those from women members of farming households. The grain yield of CR 2624, IR 74371-70-1-1 and IR 74371-3-1-1 were higher than the local check and farmers preferred CR 2624 for a range of other pre and post-harvest traits even though they disliked its late maturity (Table 2). Farmers of target environments selected cultivars on the basis of mid early/or medium duration (up to 110 days), grains panicle ${ }^{-1}$, effective tillers hill $^{-1}$, less number of chaffy and grain type.

Grain yield selection is based on results from multi-location trials and more attention is given to testing under on-farm conditions. Farmer participatory plant breeding approaches have been integrated into the onfarm testing program to ensure that farmers will accept new cultivars. The visual combined assessment of performance and its stability is an important advantage, and adds confidence in the decision to promote a superior genotype. In the view of above discussion, the genotypes IR 74371-70-1-1 and CR 2624 recommended for cultivation under target environment in drought condition. Sahbhagi dhan (IR 74371-70-1-1), a drought-tolerant rice variety jointly developed by International Rice Research Institute, Philippines and Central Rainfed Upland Rice Research Station, Hazaribagh and CR 2624 (Pyari) for Aerobic condition by CRRI, Cuttack were released for cultivation.

\section{References}

Bandyopadhyay BB (2008). Genetic variation in wheat upon water deficit stress to a range of low temperature regime at high altitude. Indian J Genet, 68 (1): 26-32.

Deshmukh DV, Mhase LB and Jamadagni BM (2004). Evaluation of chickpea genotypes for drought tolerance. Indian J. Pulses Res., 17: 47-49.

Fischer RA and Maurer R (1978). Drought resistance in spring wheat cultivars: I. Grain yields responses. Aust. J. Agric. Res., 29: 897-907.

Fischer KS and Wood G (1981). Breeding and selection for drought tolerance in tropical maize. In: Proc. Symp. On Principles and Methods in Crop Improvement for Drought Resistance with Emphasis on Rice, IRRI, Philippines.

Fussell LK, Bidinger FR and Bieler P (1991). Crop physiology and breeding for drought tolerance: research and development. Field Crops Res., 27 (3): 183-199.

Pandey S, Bhandari H and Hardy B (2007). Economic costs of drought and rice farmers coping mechanism. International Rice Research Institute, Los Banos, Philippines. 203 p.

Parameshwarappa SG and Salimath, PM (2008). Field Screening of Chickpea Genotypes for Drought Resistance. Karnataka J. Agric. Sci., 21(1): 113114.

Prakash V (2007). Screening of wheat (Triticum aestivum L.) genotypes under limited moisture and heat stress environments. Indian J. Genet., 67 (1): 
31-33.

Virk DS and Witcombe JR (2008). Evaluating cultivars in unbalanced on-farm participatory trials. Field Crops Res., 106: 105-115.

Winter SR, Musick JT and Porter KB (1988). Evaluation of screening techniques for breeding drought resistance winter wheat. Crop Sci., 28: 512-516.

Wonprasaid S, Khunthasuvon S, Sittisuang P and Fukai S (1996). Performance of contrasting rice cultivars selected for rainfed lowland conditions in relation to soil fertility and water availability. Field Crops Res., 47: 267-275.

\section{How to cite this article:}

Mall, A.K., P. Swain and Singh, O.N. 2017. Identifying Drought Tolerant Genotypes of Rice (Oryza sativa L.) Using Participatory Research Approach for Resource Poor Farmers of Orissa. Int.J.Curr.Microbiol.App.Sci. 6(7): 182-188. doi: https://doi.org/10.20546/ijcmas.2017.607.021 